Article

\title{
Perfume Encapsulation via Vapor Induced Phase Separation
}

\author{
Mario Ammendola 1,2,3,*(D), Raul Rodrigo Gomez ${ }^{3}$ and Ricard Garcia Valls 1,2,4 \\ 1 Departament $d^{\prime}$ enginyeria química, Universitat Rovira i Virgili, Av. dels Països Catalans 26, \\ 43007 Tarragona, Spain; ricard.garcia@urv.cat \\ 2 Centre Tecnològic de la Química de Catalunya, Carrer Marcelli Domingo s/n, 43007 Tarragona, Spain \\ 3 Procter \& Gamble Services Company n.v., Temselaan 100, 1853 Strombeek-Bever, Belgium; \\ rodrigogomez.r@pg.com \\ 4 Eurecat, Centre Tecnològic de Catalunya, C/Marcellí Domingo s/n, 43007 Tarragona, Spain \\ * Correspondence: mario.ammendola1@estudiants.urv.cat
}

Received: 23 October 2019; Accepted: 15 November 2019; Published: 20 November 2019

check for updates

\begin{abstract}
In this study we explored the implementation of the vapor induced phase separation (VIPS) to produce cellulose acetate microcapsules for the encapsulation of a complex mix of fragrances. VIPS is a technique used for membrane preparation, but barely mentioned for microencapsulation. We compared the products from VIPS and a more common microencapsulation process, the immersion precipitation technique (IPS). The capsules prepared via VIPS show a core-shell structure with a thin polymeric shell surrounding the internally empty space, conversely to those produced via IPS, showing an incomplete spherical morphology. This can be attributed to a better control of the precipitation rate of the encapsulation material in the non-solvent thanks to the longer exposition time to the vapor. The activity and encapsulation efficiency of the capsules, obtained through TGA analysis, reached a maximum of $\approx 75 \%$ and $\approx 90 \%$, respectively. Moreover, a growing trend between the initial active concentration and the encapsulation efficiency is noticed.
\end{abstract}

Keywords: cellulose acetate; fragrance; encapsulation; sustainable; VIPS

\section{Introduction}

Fragrance chemicals are widely used nowadays to enhance the consumer's enjoyment for several consumer goods, such as personal care products, laundry detergents, and fabric softeners [1]. However, fragrances generally exhibit high volatility, resulting in the loss of their aroma when exposed to the atmosphere [2]. Among the technologies developed to overcome this issue, the most commonly used is the microencapsulation of the fragrance materials in a protective coating.

Microencapsulation offers an ideal and unique carrier system for active ingredients, allowing the controlled and targeted release, isolation, and protection of the active compounds and improved stability and efficacy [3]. Several preparation technologies for the encapsulation of core material have been reported and, among them, phase inversion precipitation is quite common.

Briefly, this technique is based on the interaction of at least three compounds: a polymer, a solvent for the chosen polymer, and a non-solvent for the polymer. The solvent and non-solvent should be miscible with each other [4]. Between the several different ways in which it is possible to induce the phase separation, the immersion precipitation technique (IPS) is probably the most common for microcapsules production. In that specific technique a polymer solution (polymer and solvent) is cast on a suitable support and immersed in a coagulation bath containing the non-solvent. The precipitation occurs because of the exchange of the solvent and non-solvent. The solvent diffuses into the coagulation bath, whereas the non-solvent will diffuse into the cast film. After a certain time, 
the exchange of solvent and non-solvent proceeds until the solution becomes thermodynamically unstable and de-mixing takes place [5]. This process is very fast and is usually completed within a few seconds, which makes it almost impossible to determine the kinetics [6]. The liquid-liquid de-mixing is associated to the Flory-Huggins interaction parameter between the polymer and the non-solvent $\left(\chi_{13}\right)$. In our case, considering cellulose acetate and water, it is $[1,4,7]$. This leads to rapid liquid-liquid de-mixing when the polymer solution comes into contact with the coagulation bath.

Vapor induced phase separation (VIPS) is a similar process that involves a dry-wet casting process; the dope solution is exposed to non-solvent vapor prior to immersion in a coagulation bath. It can be considered as an intermediate process between the IPS and the controlled solvent evaporation. In solvent evaporation, however, the non-solvent is originally contained in the solution, along with the polymer and a more volatile solvent. Due to that, the phenomenon responsible for phase separation is the solvent outflow, while in VIPS is the non-solvent outflow. For that reason, VIPS is more assimilable to a wet method, where the initial solution composed by polymer and solvent is immersed in a non-solvent bath. By using non-solvent vapor instead of the liquid non-solvent, the process becomes much slower and controlling the whole process becomes possible. The mass transfer rates, indeed, are considerably reduced compared to those associated with a wet process [8]. Due to this advantage, VIPS became a quite common technique for membrane preparation, and several articles can be found [9-12]. Despite the great interest in this technique regarding the production of membranes, it is not a common method for microcapsules preparation. As far as we know, polysulfone microcapsules were prepared by using that technique [13], but apart from that, no other publications have been found in literature.

Cellulose acetate (CA) is the most widely used ester of cellulose [14]. In a world where environmental protection is becoming increasingly important, cellulose acetate is playing an increasingly important role since it is a green polymer and that it derives from acetyl substitution of cellulose, which is the most abundant organic polymer on Earth $[15,16]$.

The biodegradability of CA has been subject of attention for many years and numerous studies have been conducted to assess it. Currently, CA is generally recognized as a biodegradable polymer within the scientific community [17-20]. The active material to encapsulate is a complex mix of fragrance molecules made to improve the freshness and enjoyability of consumer goods related to home-care and personal-care applications.

In this work, we focused our attention on the VIPS technique, exploring the possibilities to implement the process for capsules preparation. We compared CA microcapsules prepared via IPS and VIPS, noticing the interesting opportunities offered from this technique.

\section{Materials and Methods}

Cellulose acetate $\left(\mathrm{Mn} \approx 30.000 \mathrm{gmol}^{-1}\right)$ and Acetone were purchased from Sigma-Aldrich (Madrid, Spain). Glacial acetic acid was purchased from Scharlab (Barcelona, Spain). All the compounds were used as received without any further purification. The technical accord was prepared and supplied by Procter \& Gamble (Brussels, Belgium).

Microcapsules were prepared via IPS and VIPS. The preparation of the solution was the same for both. A 3\% or $6 \%$ CA solution in 30:70 (wt \%) acetic acid/acetone mixture was prepared. Then, a certain amount of active was added in the solution and the solution was stirred for $24 \mathrm{~h}$.

For the IPS, an airbrush, constituted by an air-atomizing nozzle $(0.8 \mathrm{~mm}$ diameter) was used to disperse the polymeric solution by a simple shearing action, which was provided by a compressed air stream. Air pressure was set at 2.5 bar. The airbrush was positioned in such a way that the outlet flow direction was perpendicular to the surface of a water precipitation bath. The nozzle was located at different distances from the precipitation bath and the water content of the bath was varied as well, to observe possible influence of the microcapsules production. The precipitation bath was always stirred. When the polymeric solution microdroplets were in contact with the precipitation bath, microparticles began floating on it immediately. Particles removal was necessary after a while to avoid collision with the new microdroplets and aggregates. Therefore, the production of particles was stopped regularly 
and the liquid in the precipitation bath was filtered using a $0.8 \mu \mathrm{m}$ nylon filter. The microparticles were then collected into a vial and stored for further analysis.

The main difference between the previous technique and the VIPS technique is in the use of non-solvent vapor prior to immersion in the coagulation bath. For this purpose, the airbrush was placed into a chamber, which has been specially designed and built for this work. The chamber dimensions were $110 \times 30 \times 30 \mathrm{~cm}^{3}$ (length $\times$ width $\times$ height). The chamber was designed with this dimension after the observation of the outflowing sprayed flux of solution at the selected pressure of 2.5 bar. For achieving a highly humid atmosphere inside the chamber, a compressed air flow was forced to pass through a bubble bottle containing distilled water and, in addition, heated to $80^{\circ} \mathrm{C}$ in a water bath, to increase water content in the air flow. The conditions of temperature and relative humidity inside the chamber were controlled through a hygrometer and they were $25^{\circ} \mathrm{C}$ and $95 \%$, respectively. At the bottom of the chamber, a $300 \mathrm{~mL}$ water precipitation bath was placed to complete the solvent/non-solvent exchange and complete the particles formation. When the surface of the water bath was covered by the microparticles, the production was stopped. The resulting products were filtered using a $0.8 \mu \mathrm{m}$ nylon filter. The microparticles were then collected into a vial.

The microcapsules morphology was investigated by means of ESEM FEI Quanta 600 apparatus (Thermo Fisher Scientific, Hillsboro, OR, USA). To obtain the microcapsules cross-section micrographs without modifying their structure, they were cryogenically cut [21]. First microcapsules were attached over a specimen disc with a freezing medium. An embedding medium for frozen tissue specimens was used (Tissue-Tek, OCT Compound, Sakura Tissue, Alphen aan den Rijn, The Netherlands). Once the capsules were fixed over the specimen disc, the disc was immersed into a liquid nitrogen bath in order to freeze the sample. Next, the specimen disc was located in the cryochamber. Then, the sample was cut with thickness intervals of $1 \mu \mathrm{m}$ at $-20^{\circ} \mathrm{C}$ and deposited over a glass. Finally, the cross-sections were analyzed by ESEM.

Microcapsules mean size was determined using a HELOS BR supplied by Sympatec GmbH System Partikel Technik (Sympatec $\mathrm{GmbH}$, Clausthal-Zellerfeld, Germany) equipped with a R1 cuvette and a Helium-Neon Laser $5 \mathrm{~mW}$ max output at $633 \mathrm{~nm}$. The analysis of $0.1 \mathrm{~g}$ of the microcapsules was carried out in $\approx 50 \mathrm{~g}$ of water. The software setup and sample analysis were achieved using the Windox 5.8.0.0 software. The data were collected twice, at $5 \mathrm{~s}$ each.

Thermogravimetric analysis (TGA) was used to determine the activity of the capsules. Capsule activity is defined as the weight percentage of active encapsulated in the capsule. Different methods have been proposed to calculate the activity of the capsules [22], presenting slightly different results. TGA is a thermal analysis in which the changes in weight of a sample are constantly measured over time as the temperature changes. The heating rate needs to be set to avoid the overlap between the evaporation temperature of the encapsulated active materials and the temperature of the degradation of the shell. TGA response curves of the pure components, the active materials and the shell, are needed for a comparison between their response profiles and that of the capsules. This correlation is used to determine the temperature range where only the mass loss of encapsulated active occurs. Once the correct temperature range is identified, it is possible to estimate the mass of the encapsulated active (active in capsules) as the weight loss of the capsules in that temperature range. The encapsulation efficiency (EE) can be defined as the mass of encapsulated active material compared to the mass of the active material added to the initial formulation [23], as reported in Equation (1) below:

$$
E E=\frac{\text { active in capsules }}{\text { total active }}
$$

TGA was carried out with a Mettler TGA/SDTA 851e thermo-balance (Mettler Toledo, L'Hospitalet de Llobregat, Barcelona, Spain). The samples with an approximate weight of $10 \mathrm{mg}$ were degraded between 30 and $600{ }^{\circ} \mathrm{C}$ at a heating rate of $10{ }^{\circ} \mathrm{C} \mathrm{min}^{-1}$ in nitrogen $\left(100 \mathrm{~mL} \mathrm{~min}^{-1}\right)$ measured under normal conditions. 
The stability of the dried capsules was evaluated by means of TGA analysis, as described before. Samples of the capsules in powder form were stored in an ambient condition and the TGA was performed at different times. The activity of the capsules at $t=0$ (freshly prepared capsules) was compared to the activity after six months and one year.

\section{Results}

In Figure 1, the products of the IPS process are showed. The formation of the shell was interrupted before a complete spherical structure was reached. The morphology of the product is very homogeneous and their internal structure appears composed of a thin polymeric layer surrounding an empty internal volume.
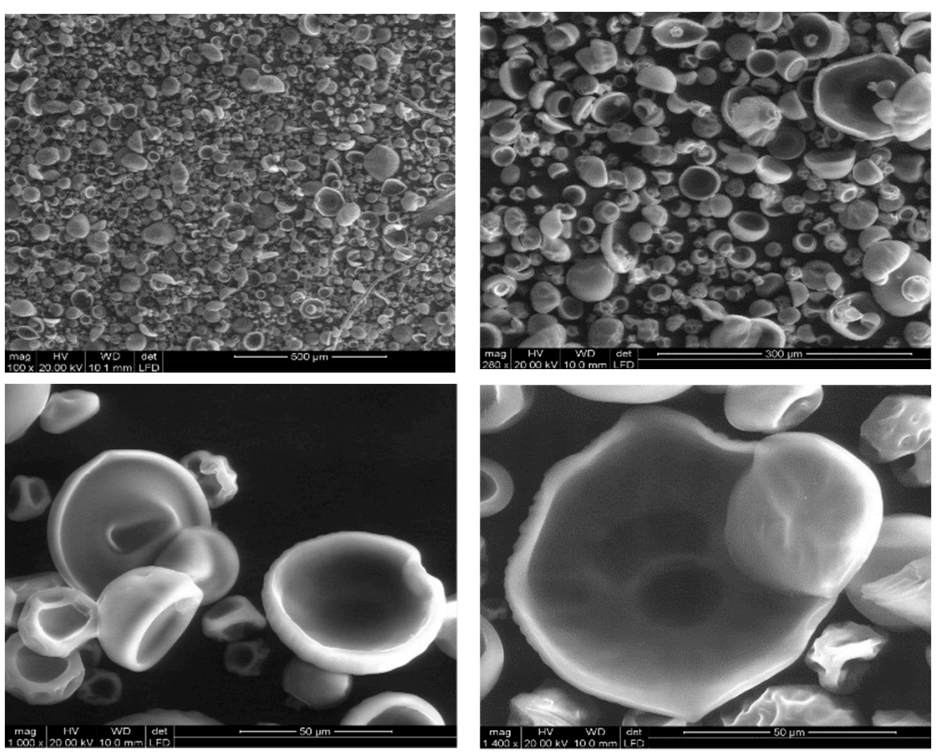

Figure 1. Micrographs of capsules prepared via immersion precipitation (IPS) technique.

Despite several attempts to modify some parameters of the process, such as the polymer concentration and the distance between the nozzle and the bath, the morphology of the prepared capsules has not changed, and no complete formation of the shell was achieved.

Samples with different ratios between the active and polymer were prepared by VIPS technique, as reported in Table 1.

Table 1. Sample composition and process parameters of the VIPS microparticles.

\begin{tabular}{cccc}
\hline Sample & CA [wt $\%$ ] & Active: CA & RH [\%] \\
\hline VIPS1 & 3 & $1: 1$ & 95 \\
\hline VIPS2 & 3 & $3: 1$ & 95 \\
\hline VIPS3 & 3 & $5: 1$ & 95 \\
\hline
\end{tabular}

In Figure 2, generic images of the microcapsules are shown. It is possible to note the spherical and complete structure that they assume, unlike those previously shown and prepared through the IPS technique. 

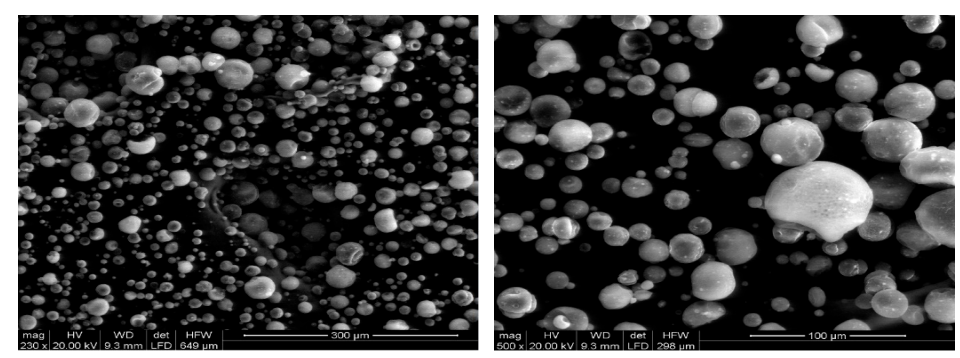

Figure 2. SEM of vapor induced phase separation (VIPS) capsules micrographs with small magnitude.

In Figure 3 the particle size distribution of the VIPS capsules is reported. The distribution is quite wide, and in fact both large capsules and much smaller capsules are present. The mean diameter resulted $51 \mu \mathrm{m} ; 80 \%$ of the capsule diameters were in the range $19-84 \mu \mathrm{m}$.

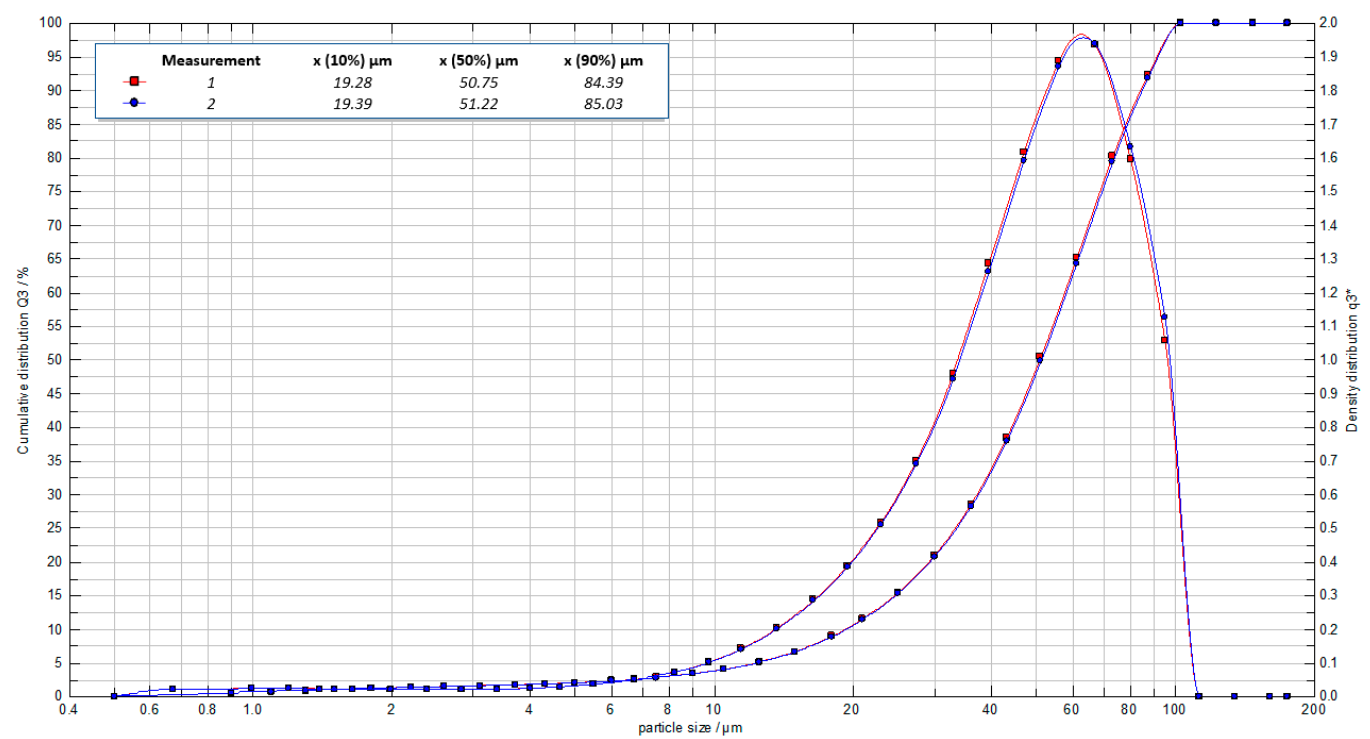

Figure 3. Particle size distribution of VIPS2.

In Figure 4 SEM images of the VIPS microcapsules are presented. The microcapsules have a rounded outer surface that show continuous walls with no fissures, cracks or interruptions. It is possible to see the microcapsules formed with different core concentrations and conclude that it is not interfering in microcapsule morphology. Ortiz et al. [24] and Rocha et al. [25] also observed that the core concentration did not interfere with particle morphology when casein hydrolysate was encapsulated using soybean protein isolate, and when lycopene was encapsulated using modified starch, respectively.

The internal structure represented in Figure 5, is obtained from the cross-section of the capsules after being cryogenically cut. The images show a layer of the polymeric shell surrounding an internally empty structure, typical of a core-shell morphology. Furthermore, the polymeric shell does not show porosity, appearing as a dense, compact and homogeneous layer. This is an essential quality to ensure lower gas permeability, better protection, and fragrance retention. 

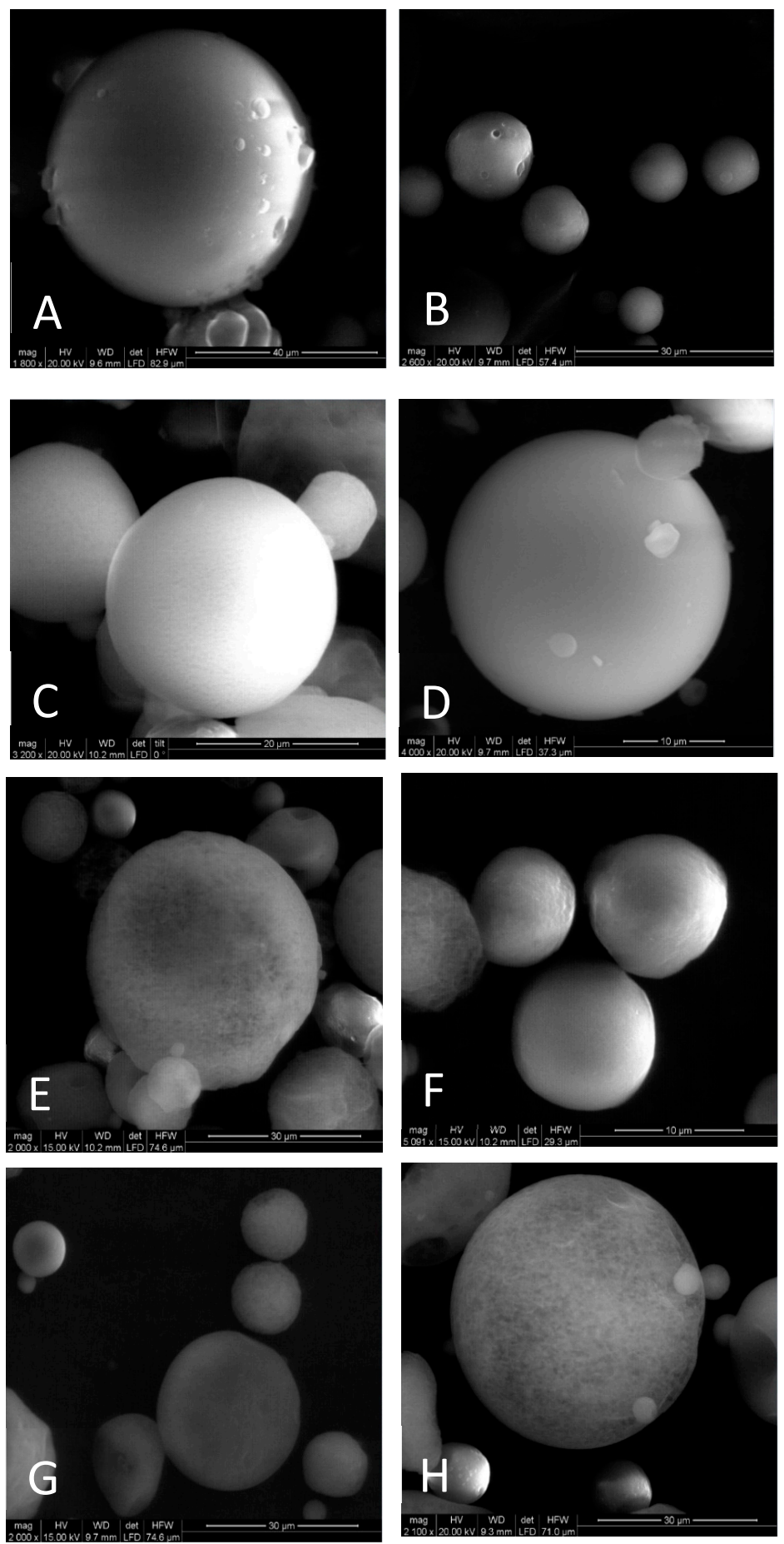

Figure 4. ESEM pictures of microcapsules prepared by VIPS technique. (A-C) VIPS 1; (D-F) VIPS 2; $(\mathrm{G}, \mathrm{H})$ VIPS 3.

By means of TGA analysis, we were able to determine the activity of the capsules, defined as the active encapsulated inside the capsules. In our case, the degradation temperature of the polymer was higher than the highest of the perfume evaporation temperature. Therefore, it is possible to choose a temperature in the interval between the degradation temperature of the polymer and the evaporation temperature of the perfume and evaluate the active content value, associable to the weight loss at that determined temperature. In Figure 6, TGA curves are shown. The red line represents the CA capsules prepared without the active. Therefore, it is possible to evaluate the weight loss associable to the core material. 

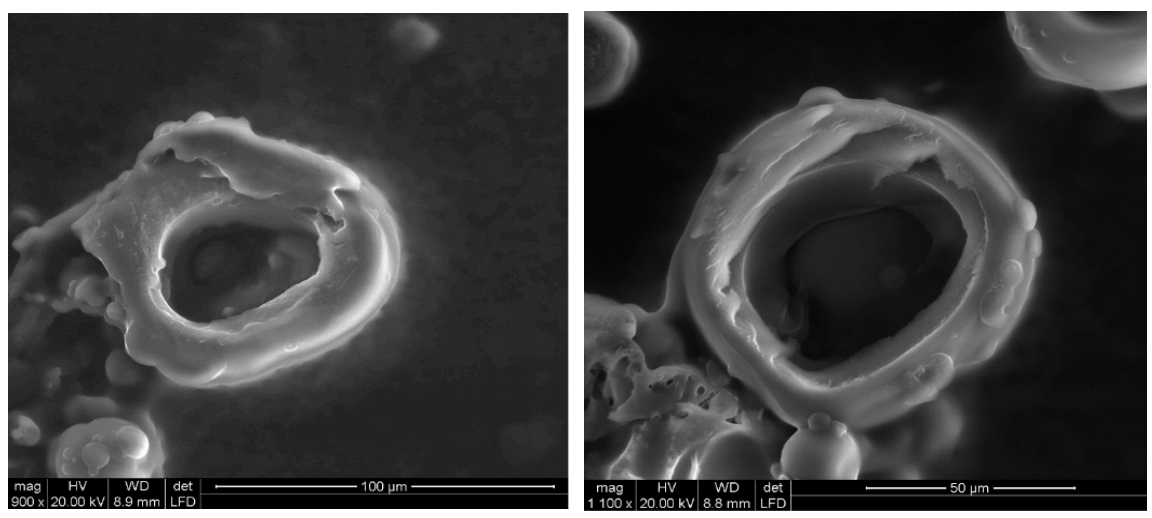

Figure 5. Cross-section of VIPS capsules.

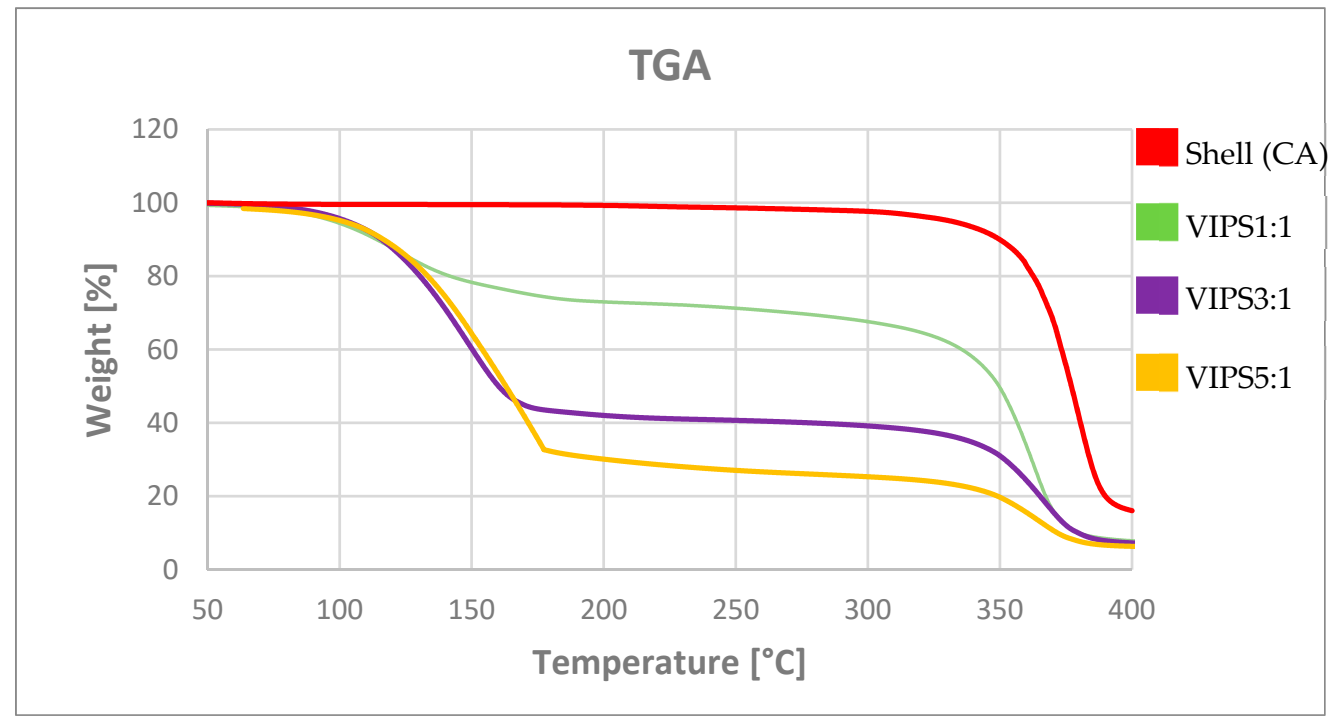

Figure 6. TGA plot of VIPS capsules.

In Table 2, the activity and the encapsulation efficiency for the VIPS capsules prepared with different core-shell ratios are summarized. It is possible to notice that increasing the active content in the polymeric solution, the activity of the capsules and thus the encapsulation efficiency increase as well. The explanation of this phenomenon could be in the saturation of the chamber. It means that once a certain concentration limit has been reached for each fragrance molecule, it is no longer possible for the active to spread within the internal space of the chamber, which is then forced to remain inside the polymeric shell of the capsule.

Table 2. Activity and encapsulation efficiency of VIPS capsules.

\begin{tabular}{ccc}
\hline Sample & Activity [\%] & EE [\%] \\
\hline VIPS 1:1 & 30 & 60 \\
VIPS 3:1 & 62 & 82.5 \\
VIPS 5:1 & 74 & 88.5 \\
\hline
\end{tabular}

The stability of the VIPS capsules was assessed in dry condition. In Figure 7, the TGA plots of the VIPS3:1 microcapsules stored for 1 year in powder form and at ambient condition are reported. 


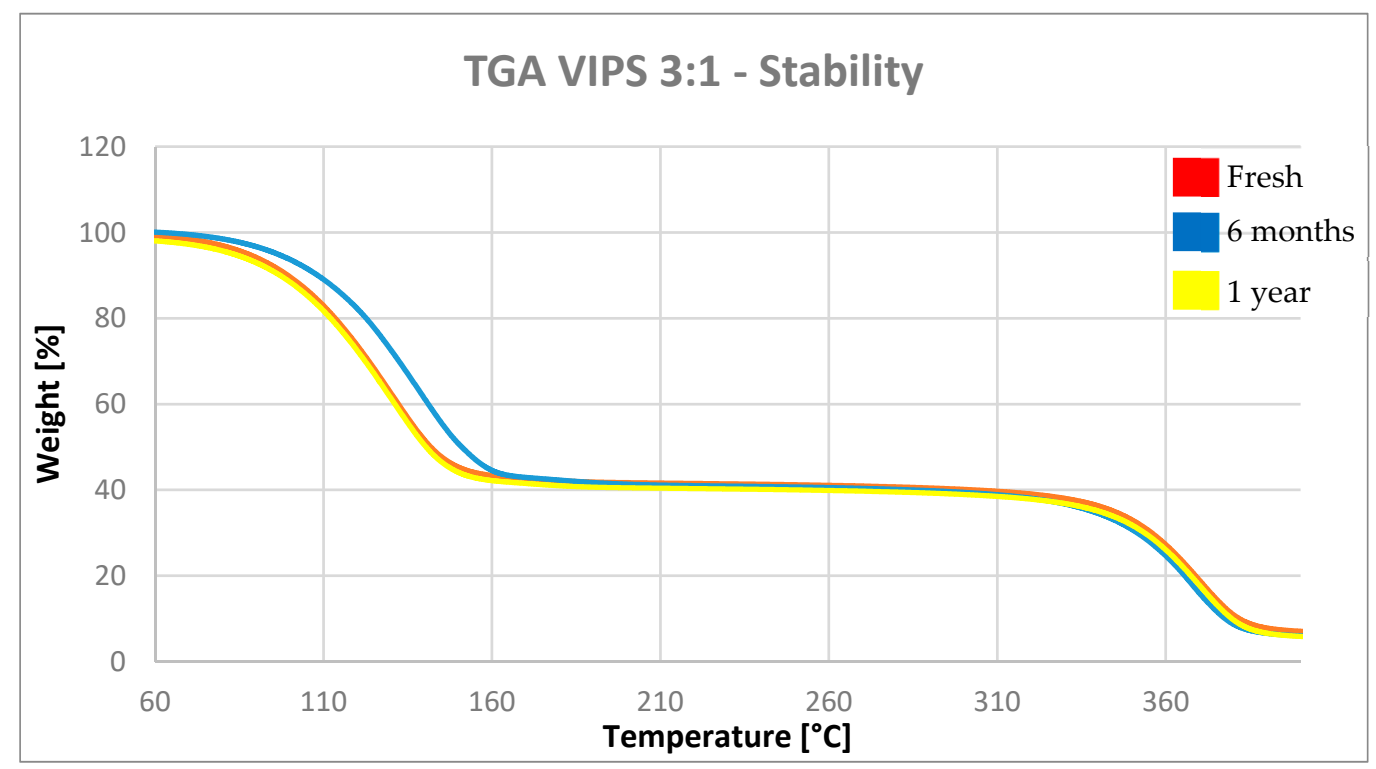

Figure 7. TGA curves of VIPS3:1 at different timing.

In Table 3, the results of the TGA analysis on the same sample are summarized.

Table 3. Activity of dry VIPS capsules at different time.

\begin{tabular}{cccc}
\hline Sample & Activity T $=\mathbf{0}[\%]$ & Activity $\mathbf{T}=\mathbf{6}$ Months [\%] & Activity T = $\mathbf{\text { Year }}$ [\%] \\
\hline VIPS 1:1 & 30.4 & 29.6 & 29.9 \\
VIPS 3:1 & 62.2 & 61.8 & 62.2 \\
VIPS 5:1 & 73.8 & 73.5 & 73.4 \\
\hline
\end{tabular}

The capsules show the same weight loss and consequently the same activity after 1 year of storage at ambient conditions. The slight difference in the value can be assimilated to the error of the measurement. The results of the analysis show that the activity of the samples does not change over time, remaining constant throughout the test. This means that the active contained within the shell does not diffuse through the polymeric material and remains contained within it in absence of external stimuli. Considering these results, we can conclude that the cellulose acetate capsules prepared in this work are stable if stored in dry and powder form, in ambient conditions.

\section{Conclusions}

Microcapsules containing a complex mix of fragrances have been tried to be prepared through the IPS and the VIPS technique. VIPS technique is a modification of the IPS, mostly used for the preparation of capsules. The main difference lies in the use of solvent vapor to promote better precipitation of the polymer through a solvent/non-solvent exchange of the solution, in a more controllable manner. This was accomplished by building a chamber and filling it with water vapor. Then, the polymer solution was sprayed using an airbrush. The results of this study show us the opportunities of the VIPS technique, by slightly changing a simple process like IPS. The main advantage stays in the controllable polymer precipitation rate through the promotion of different concentrations of non-solvent vapor in the chamber.

Through the ESEM images, it was possible to notice the different morphology reached through the two techniques and the decided increase in the achievement of a spherical and complete structure. The preparation of cellulose acetate capsules was therefore successful with the use of the VIPS technique. The key factors were the longer exposition time to the vapor of the non-solvent and the distance between the drop formation and the collection bath. By using non-solvent vapor, on the other hand, 
the kinetics of the process is slowed down and phase precipitation can occur completely before the spherical shape of the drop is lost. The obtainment of a core-shell structure was confirmed by the morphological analysis of the cross-section of the capsules.

Activity and EE of the products have been evaluated through the TGA and reach a maximum of $\approx 75 \%$ and $\approx 90 \%$, respectively, in the case of a core-shell ratio 5:1. Furthermore, a growing trend between the initial active concentration and the encapsulation efficiency is noticed. This can be attributed to the saturation of the chamber that makes it impossible for part of the active material to escape from the encapsulation process.

Moreover, the stability of the VIPS capsules was assessed in dry conditions. The capsules show a high stability, maintaining the same activity after one year; this means that there is no diffusion of the fragrances through the shell without external stimuli.

Author Contributions: Conceptualization, R.G.V. and R.R.G.; methodology; M.A., R.G.V. and R.R.G.; formal analysis, M.A.; investigation, M.A.; writing-original draft preparation, M.A.; writing-review and editing, M.A., R.R.G., R.G.V.; supervision, R.G.V., R.R.G.; project administration, R.G.V., R.R.G.; funding acquisition, R.G.V., R.R.G.

Funding: Financial support of Smartmem-Stimuli-responsive Membranes for consumer goods sustainability project under European Community's Horizon 2020 ITN Marie Curie grant agreement no. 675624.

Acknowledgments: The authors would like to acknowledge Mariana Trifonova and Mercé Moncusí from SRCiT, URV, for their support with electron microscopy analysis.

Conflicts of Interest: The authors declare no conflict of interest.

\section{References}

1. Brain, J.; Bennett, S.W.; Zhen, Y.; Pluyter, J.G.L.; Popplewell, L.M.; Lee, K.D. Encapsulated Fragrance Chemicals. U.S. Patent 7,196,049, 27 March 2007.

2. Smets, J.; Fernandez Prieto, S.; Smith, S.; Underiner, T.; Wos, J.; Huhn, W.; Frederick, H.A.; Giamberini, M.; Tylkowski, B. Encapsulates. U.S. Patent 9,890,351, 13 February 2018.

3. Casanova, F.; Santos, L. Encapsulation of cosmetic active ingredients for topical application a review. J. Microencapsul. 2015, 33, 1-17. [CrossRef] [PubMed]

4. Mishra, M. Handbook of Encapsulation and Controlled Release; CRC Press: London, UK, 2015; ISBN 978-1-4822-3234-9.

5. Lalia, B.S.; Kochkodan, V.; Hashaikeh, R.; Hilal, N. A review on membrane fabrication: Structure, properties and performance relationship. Desalination 2013, 326, 77-95. [CrossRef]

6. Sun, H.; Liu, S.; Ge, B.; Xing, L.; Chen, H. Cellulose nitrate membrane formation via phase separation induced by penetration of nonsolvent from vapor phase. J. Membr. Sci. 2007, 295, 2-10. [CrossRef]

7. Elidrissi, A.; El Barkany, S.; Amhamdi, H.; Maaroufi, A.; Hammouti, B. New approach to predict the solubility of polymers Application: Cellulose Acetate at various DS, prepared from Alfa "Stipa tenassicima" of Eastern Morocco. J. Mater. Environ. Sci. 2012, 3, 270-285.

8. Venault, A.; Chang, Y.; Wang, D.-M.; Bouyer, D. A Review on Polymeric Membranes and Hydrogels Prepared by Vapor-Induced Phase Separation Process. Polym. Rev. 2013, 53, 568-626. [CrossRef]

9. Venault, A.; Chiang, C.-H.; Chang, H.-Y.; Hung, W.-S.; Chang, Y. Graphene oxide/PVDF VIPS membranes for switchable, versatile and gravity-driven separation of oil and water. J. Membr. Sci. 2018, 565, 131-144. [CrossRef]

10. Ripoche, A.; Menut, P.; Dupuy, C.; Caquineau, H.; Deratani, A. Poly (ether imide) membrane formation by water vapour induced phase inversion. Macromol. Symp. 2002, 188, 37-48. [CrossRef]

11. Bodzek, M.; Bohdziewicz, J. Porous polycarbonate phase-inversion membranes. J. Membr. Sci. 1991, 60, 25-40. [CrossRef]

12. Kang, J.S.; Lee, S.H.; Huh, H.; Shim, J.K.; Lee, Y.M. Preparation of chlorinated poly (vinyl chloride)-g-poly(N-vinyl-2-pyrrolidinone) membranes and their water permeation properties. J. Appl. Polym. Sci. 2003, 88, 3188-3195. [CrossRef]

13. Panisello, C.; Garcia-Valls, R. Polysulfone/Vanillin microcapsules production based on vapor induced phase inversion precipitation. Ind. Eng. Chem. Res. 2012, 51, 15509-15516. [CrossRef] 
14. Edgar, K.J.; Buchanan, C.M.; Debenham, J.S.; Rundquist, P.A.; Seiler, B.D.; Shelton, M.C.; Tindall, D. Advances in cellulose ester performance and application. Prog. Polym. Sci. 2001, 26, 1605-1688. [CrossRef]

15. Klemm, D.; Heublein, B.; Fink, H.-P.; Bohn, A. Cellulose: Fascinating Biopolymer and Sustainable Raw Material. Angew. Chem. Int. Ed. 2005, 44, 3358-3393. [CrossRef] [PubMed]

16. Zhang, S.; Wang, K.Y.; Chung, T.-S.; Chen, H.; Jean, Y.C.; Amy, G. Well-constructed cellulose acetate membranes for forward osmosis: Minimized internal concentration polarization with an ultra-thin selective layer. J. Membr. Sci. 2010, 360, 522-535. [CrossRef]

17. Buchanan, C.M.; Gardner, R.M.; Komarek, R.J. Aerobic biodegradation of cellulose acetate. J. Appl. Polym. Sci. 1993, 47, 1709-1719. [CrossRef]

18. Gardner, R.M.; Buchanan, C.M.; Komarek, R.; Dorschel, D.; Boggs, C.; White, A.W. Compostability of cellulose acetate films. J. Appl. Polym. Sci. 1994, 52, 1477-1488. [CrossRef]

19. Komarek, R.J.; Gardner, R.M.; Buchanan, C.M.; Gedon, S. Biodegradation of radiolabeled cellulose acetate and cellulose propionate. J. Appl. Polym. Sci. 1993, 50, 1739-1746. [CrossRef]

20. Gu, J.-D.; Eberiel, D.T.; McCarthy, S.P.; Gross, R.A. Cellulose acetate biodegradability upon exposure to simulated aerobic composting and anaerobic bioreactor environments. J. Environ. Polym. Degrad. 1993, 1, 143-153. [CrossRef]

21. Torras, C.; Pitol-Filho, L.; Garcia-Valls, R. Two methods for morphological characterization of internal microcapsule structures. J. Membr. Sci. 2007, 305, 1-4. [CrossRef]

22. Feng, T.; Liu, F.; Wang, X.; Shuang, H.; Re, Y.; Rong, Z.; Liu, Y. Evaluation of Different Analysis Methods for the Encapsulation Efficiency of Amylose Inclusion Compound. Int. J. Polym. Sci. 2015, 2015, 645916. [CrossRef]

23. Ferreira, I.V.W.; Focke, W.W.; du Toit, E.L. Spontaneous microencapsulation of geraniol by zein. Express Polym. Lett. 2018, 12, 986-995. [CrossRef]

24. Molina Ortiz, S.E.; Mauri, A.; Monterrey-Quintero, E.S.; Trindade, M.A.; Santana, A.S.; Favaro-Trindade, C.S. Production and properties of casein hydrolysate microencapsulated by spray drying with soybean protein isolate. LWTFood Sci. Technol. 2009, 42, 919-923. [CrossRef]

25. Rocha, G.A.; Fávaro-Trindade, C.S.; Grosso, C.R.F. Microencapsulation of lycopene by spray drying: Characterization, stability and application of microcapsules. Food Bioprod. Process. 2012, 90, 37-42. [CrossRef] 